DOI: 10.20472/IAC.2018.037.017

\title{
LYUBA SPASOVA
}

Institute for the Study of Societies and Knowledge, Bulgarian Academy of Sciences, Bulgaria

\section{MIGRANTS AND REFUGEES - PERCEPTIONS, ATTITUDE AND SOCIAL DISTANCE. DATA FROM BULGARIA}

\begin{abstract}
:
Part of a larger research focused on deviance in the context of intensified migration, the study explores changes in the perceptions of Bulgarians towards migrants and refugees coming to the country or passing by in large numbers in their way to West Europe. Although Bulgaria continues to be predominantly a country of origin of migration, we are currently observing a change of attitudes and reduced solidarity towards migrants and refugees in the country.

Drawing on data from a set of representative surveys, we are able to reconstruct a detailed picture of the perceptions and social distance towards migrants. What is more, the design of the survey and samples, enables us to make a comparison and distinction between attitudes of respondents living near centers for temporary accommodation of refugees and the general population, i.e. to study the role and importance of proximity and involvement for social distance, solidarity and perception of migrants and refuges as threat.
\end{abstract}

\section{Keywords:}

migration, attitudes, social distance

JEL Classification: A14, D74 